\title{
LUIS ENRÍQUEZ XOAIDA, EL PRIMO HERMANO MORISCO DEL REY CATÓLICO (análisis de un caso de falsificación histórica e integración social)
}

\author{
Javier Castillo Fernández
}

\section{LA RENOVACIÓN HISTORIOGRÁFICA EN TORNO}

\section{A LA ASIMILACIÓN DE LOS MORISCOS}

En los últimos años la historiografía de los moriscos, tan abundante y de tendencia tan diversa, ha experimentado un giro en la concepción teórica de la minoría ${ }^{1}$. El nudo gordiano parece centrarse en el tema de la asimilación y su corolario (enfrentamiento, difícil convivencia entre etnias) ${ }^{2}$. Hasta hace poco tiempo el debate estaba estancado en la teoría braudeliana del "conflicto de civilizaciones", es decir, en el enfrentamiento étnico-religioso. Sorprende comprobar cómo se obviaban descaradamente las vertientes económica y social del problema.

No creemos que sea tan importante demostrar que la mayoría de los moriscos exan criptomusulmanes, pues caeríamos de nuevo en el maniqueísmo de los apologistas de la época y sufriríamos el desenfoque del famoso "envenenamiento de fuentes" (fundamentalmente inquisitoriales) que sólo muestran lo excepcional, lo que diferenciaba al converso. Se han ocultado un sinfín de elementos que unían a las dos comunidades, toda una serie de relaciones económico-sociales, que es donde se encuentra a nuestro entender el problema central de la cuestión. Intentar reducir la dialéctica cristianos-moriscos a un enfrentamiento étnico-religioso, en definitiva superestructural, es

1. Sin duda el detonante fue el denso y espléndido artículo de Francisco MÁrQuEZ. VILLANUEVA: «El problema historiográfico de los moriscos», Bulletin Hispanique, 86, 1984, nos 1-2, pp. 61-135, reeditado en su obra recopilatoria El problema morisco (desde otras laderas), Madrid, 1991.

2. Garcia-Arenal, M.: «El problema morisco: propuestas de discusión», Al-Qantara, XIII, fasc. 2, 1992, pp. 491-503. 
intentar ocultar toda una serie de tensiones, las verdaderamente importantes, provocadas por un determinado orden impuesto. Es entonces cuando descubrimos lo mucho que aún nos queda por conocer.

Muy poco sabemos de la estructuración social de las diversas comunidades moriscas de la Corona de Castilla ${ }^{3}$. Se suele etiquetar a los moriscos como una clase social, casta o minoría marginada dentro de la sociedad del Antiguo Régimen; cuando en realidad se estructuraban en diferentes niveles de riqueza al igual que la sociedad en que se imbricaban. Aunque la inmensa mayoría de los moriscos vivía bajo un régimen de dominación también existían dentro de este grupo privilegiados y opresores. La existencia de élites moriscas de tipo medio está comprobada para el Reino de Granada en el siglo XVI. Su importancia como intermediarios entre el poder del Estado y la masa de conversos ha quedado de manifiesto meridianamente ${ }^{4}$.

Casi nada conocemos del desarrollo económico de las comunidades moriscas, de las relaciones laborales entre los cristianos nuevos y viejos, de su importancia, hasta ahora desconocida, en algunos sectores económicos. Los abundantes y difíciles protocolos notariales guardan infinidad de sorpresas y muchas respuestas para el historiador interesado en conocer en profundidad el desarrollo de la vida de este diversificado grupo social.

Dentro del Reino de Granada las diferencias regionales eran muy importantes. El estereotipo que ha funcionado hasta hace poco tiempo, fijado definitivamente por Caro Baroja ${ }^{5}$, fue paradójicamente el del más aislado y desconocido en la época, el del morisco de la montaña, fundamentalmente el alpujarreño: pequeño propietario agrícola, inasimilado culturalmente y de carácter levantisco. En definitiva, el mismo que interesaba destacar desde el poder para justificar su política represiva. Pero han quedado en la sombra masas de moriscos residentes en zonas de población mixta como ciudades y grandes pueblos situados en zonas llanas donde la aculturación era ya importante (una buena parte conocía y utilizaba el castellano) y la diferenciación social más evidente: grandes propietarios de tierras y ganado con objetivos comerciales, mercaderes acomodados, artesanos de todo tipo... La pregunta es si este olvido de los historiadores ha sido inconsciente o simplemente estas categorías no encontraban acomodo dentro del rígido esquema. de conflicto de culturas. El problema se complica cuando comprobamos que algunos segmentos de población morisca de estos ámbitos geográficos, no hace falta aclarar que los más pudientes, eligen integrarse totalmente al imi-

3. La última aportación de conjunto la constituyen los sugerentes trabajos de Serafín de TAPIA, fundamentalmente su obra La comunidad morisca de Avila, Salamanca, 1991.

4. SORIA MESA, E.: «De la conquista a la asimilación. La integración de la aristocracia nazarí en la oligarquía granadina. Siglos XV-XVII», Areas. Revista de Ciencias Sociales, 14, 1992, pp. 51-64.

5. Caro Baroja, J.: Los moriscos del Reino de Granada, Madrid, 1985 (3 ed.). 
tar los hábitos culturales dominantes a la par que rechazaban, al menos externamente, buena parte de sus señas de identidad (vestido, lengua coloquial, costumbres alimentarias...). Estas clases emergentes, en buena medida apoyadas por el poder de la Corona, son las que nos interesan actualmente. Si conocíamos a los pequeños agricultores inasimilados y comenzamos a saber algo de la nobleza asimilada de origen musulmán bueno sería adentrarnos en el devenir de estas clases medias.

\section{LA INTEGRACIÓN DE LOS MORISCOS BASTETANOS: UN INTENTO DE PERIODIZACIÓN}

Como ha señalado recientemente un buen conocedor de los moriscos valencianos, Santiago Laparra, es necesario abordar el estudio de las comunidades moriscas dentro de un ámbito geográfico delimitado y sin caer en el localismo ${ }^{6}$. La región geohistórica que conocemos más en profundidad la constituía en el siglo XVI la ciudad de Baza y su inmensa jurisdicción que incluía las cinco villas de su entorno (Benamaurel, Caniles, Cúllar, Freila y Zújar) y dos pequeñas alquerías en el obispado de Almería (Macael y Laroya). La localidad contaba con una importante minoría de conversos, unos quinientos vecinos, que suponían una cuarta parte de la población. En su tierra, formada en su mayoría por grandes villas de entre 250 y 600 vecinos, eran mayoritarios los moriscos aunque a lo largo del siglo XVI se fueron asentando algunos contingentes de cristianos viejos. Las bases económicas de la comarca las constituían la agricultura (que combinaba por igual el pequeño minifundio de regadío y morales que la gran propiedad de secano centrada en un cortijo, además de un importante sector viti-vinícola), la ganadería (especialmente la ovina orientada a la exportación de lana), los aprovechamientos del monte (leña, madera...), la artesanía (fundamentalmente de textiles, cueros, alfarería...) y el comercio regional e intercomarcal.

Tras la conquista castellana de fines del siglo XV se procedió al reparto de la totalidad de las tierras y casas de la ciudad y de algunas de las propiedades de musulmanes huidos en las villas del alfoz. De tal forma que la estructura de la propiedad agraria estaba dominada en buena parte por cristianos poderosos que estaban representados en el concejo de la ciudad ${ }^{7}$ y por diversas instituciones religiosas (monasterios, abadía...). A lo largo del siglo extendieron sus propiedades mediante compras, mercedes del ayuntamiento

6. La PARRa López, S.: «Moros y cristianos en la vida cotidiana: ¿historia de una represión sitemática o de una convivencia frustrada?», Revista de Historia Moderna (Anales de la Universidad de Alicante), 11, 1992, pp. 143-174.

7. CASTillo FERNÁNDEZ, J.: «El origen del concejo y la formación de la oligarquía ciudadana en Baza (1490-1520)», Chronica Nova, 20, 1992, pp. 39-73. 
y de la Corona y usurpaciones de baldíos por toda la jurisdicción. A pesar de ello los moriscos del alfoz continuaron siendo en su gran mayoría propietarios de las tierras que cultivaban. En Baza la situación fue diferente. Los musulmanes, una vez producido el reparto de sus bienes, fueron confinados en un arrabal (la collación de San Juan o Morería) para servir de jornaleros y arrendatarios de las tierras entregadas a los castellanos. Poco a poco consiguieron recuperar parte de las propiedades, rústicas y urbanas, confiscadas mediante un todavía desconocido proceso de compras que culminó con la recuperación de en torno a un $10 \%$ de estos predios, fundamentalmene tierras de regadío y de huerta cercanas al barrio ocupado por los moriscos ${ }^{8}$. Durante el siglo XVI, además, se produjo un importante incremento demográfico en la comunidad conversa bastetana debido al crecimiento vegetativo y a la inmigración de compatriotas de otras zonas más pobres, fundamentalmente de la colindante comarca del Río Almanzora.

La agricultura no era la dedicación exclusiva de los descendientes de moros. Tanto la ganadería (algunos "señores de ganado" moriscos eran hermanos de la Mesta local) como la artesanía y el comercio ocupaban a buena parte de la comunidad. En la ciudad de Baza existían en la época de la conquista, según su Libro de Repartimiento, cerca de doscientas tiendas lo que nos puede dar idea de la importancia de su pujanza comercial que se extendía por buena parte del sureste peninsular (sur de Jaén y de La Mancha, buena parte del Obispado de Almería y del Reino de Murcia...). Los mercaderes moriscos bastetanos eran especialmente emprendedores y acaudalados.

Esto por lo que corresponde a las estructuras socioeconómicas en que se desenvolvieron los moriscos de la ciudad y su tierra durante casi cien años. Existían, sin embargo, otros rasgos diferenciadores de la comunidad que analizamos. En primer lugar la ciudad de Baza fue el núcleo que contó con mayor cantidad de conversiones voluntarias al cristianismo durante la década final del siglo $\mathrm{XV}$, como ha puesto de manifiesto Pérez Boyero ${ }^{9}$. También se produjeron varios matrimonios mixtos entre repobladores y musulmanas convertidas. Todavía no está claro el porqué de esta relativa abundancia de bautismos pero algunos indicios apuntan, aparte del interés por conservar sus bienes y su vecindad (algunos incluso accedieron a nuevas propiedades en el repartimiento), al contacto con la cultura cristiana debido a su condición fronteriza (que había provocado que la zona hubiese caído varias veces en poder de Castilla entre el siglo XIII y la primera mitad del

8. Castillo Fernández, J.: «Las propiedades de sus vecinos. El Ramo de Censos Sueltos de la Renta de Poblacion del reino de Granada y la venta de bienes moriscos en la ciudad de Baza (1572-1592)», en Barrios Aguilera, M. y AndújAR CASTILlo, F. (eds.): Hombre y territorio en el Reino de Granada (1570-1630). Estudios sobre repoblación, Almería-Granada (en prensa).

9. PEREZ BOYero, E.: Contribución al estudio de las conversiones voluntarias en el reino de Granada (1482-1499), memoria de licenciatura inédita, Universidad de Málaga, 1991. 
XV) y a la influencia de la noble familia que dominó los destinos de la ciudad durante buena parte del Antiguo Régimen: los Enríquez de Guzmán.

En segundo lugar, la conversión masiva y obligatoria de los mudéjares de Baza y su tierra, ocurrida al igual que en el resto del reino durante el cambio de centuria, se produjo tras la intensa negociación de los notables locales con la Corona; recogida en las cláusulas de la capitulación que los estudiosos consideran como la más generosa de todas las firmadas entonces ${ }^{10}$. Dos autores clásicos, Gallego Burín y Gámir Sandoval, interpretaban esta magneficiencia de los reyes a causa de lo supuestamente levantiscos que eran los musulmanes de la zona pero parece obvio que obedecía a todo los contrario: la falta de problemas y la lealtad demostrada y garantizada por las élites de la minoría ${ }^{11}$.

Las comunidades moriscas del alfoz bastetano estaban perfectamente organizadas, conocían y exigían sus derechos llegando en muchas ocasiones en sus reivindicaciones hasta las últimas instancias judiciales y gubernativas como la Chancillería de Granada o el Consejo de Castilla ${ }^{12}$. La lealtad al poder establecido se demostró reiteradamente a lo largo de la centuria en los momentos más delicados: regencia de Cisneros ${ }^{13}$, papel neutral en las Comunidades y en la sublevación de las Alpujarras...

Ni que decir tiene que no todos los estamentos sociales del colectivo contaban con el mismo protagonismo ni grado de integración. Eran las élites político-económicas las que más se relacionaban con la comunidad cristiana. A nivel institucional toda una serie de colaboracionistas prestaba su apoyo y ostentaba todo tipo de cargos. Dentro del concejo de la ciudad existían dos regidurías vitalicias reservadas a los moriscos, según se recogía en la capitulación ${ }^{14}$. Los cabildos de las villas estaban ocupados por alcaldes y regidores moriscos elegidos anualmente por la ciudad, contando con escasas compe-

10. GALÁn SÁNCHEZ, A.: «Notas para una periodización de la historia de los moriscos granadinos. De las capitulaciones de la conversión a las medidas de la Capilla Real», III Coloquio de Historia Medieval de Andalucía, Jaén, 1985, pp.77-98. De esta capitulación, cuyo original se encuentra en el Archivo General de Simancas (en adelante A.G.S.), Patronato Real, 11-11, se conserva una copia en el Archivo Histórico de la Ciudad de Granada, sección Guerra, leg. 1930 , año 1500 .

11. Gallego Burín, A. y Gamir SAndoval, A.: Los moriscos del reino de Granada según el Sinodo de Guadix en 1554, Granada, 1968, p. 26. Ya criticamos esta visión en nuestro trabajo «Mudéjares y moriscos en la Tierra de Baza (1488-1508)», $2^{\circ}$ Congreso de Historia de Andalucía, Córdoba, 1991 (en prensa).

12. Así, los moriscos de Baza, Caniles, Benamaurel, Zújar y Cúllar nombraron un solicitador y procurador general para sus pleitos en 1564 (Archivo de la Alhambra, L-11, pieza 64).

13. Los representantes de las aljamas de Baza y su alfoz mostraron su apoyo al Cardenal Cisneros tras el fallecimiento de Fernando el Católico y le avisaron de posibles disturbios en la ciudad de Almería en febrero 1516 (A.G.S., Estado, leg. 3, f. 171)

14. "Ytem que ayamos de hazerles merçed de dos regimientos de aquella çibdad para dos personas honrradas que les fueren nonbradas por los buenos honbres nuevamente convertidos della para que en el dicho regimiento myren por las cosas que a ellos tocan". 
tencias. En los pueblos la figura principal era la del alguacil, cargo reservado a determinadas familias eminentes, algunas desde época musulmana ${ }^{15}$.

Otro oficio de gran relevancia y poder era el de repartidor de la farda, denominación que se daba a toda una serie de cuantiosos servicios en dinero que estaban obligados a pagar los moriscos del Reino de Granada ${ }^{16}$. Esta labor era fundamental y se realizaba también por conversos de alcurnia que se encargaban de distribuir entre la comunidad las pechas individuales a partir de un empadronamiento de los bienes de cada vecino. En teoría debían de estar asesorados en esta labor por seis honrados moriscos (dos ricos, dos medianos y dos pobres), que conocieran al vecindario y su riqueza: los famosos seises o conocedores, elegidos popularmente. A pesar de esto eran muy frecuentes las quejas de los moriscos denunciando a los repartidores por corrupción, eliminación de parientes y clientes de los padrones, aumento de las cargas a sus enemigos, etc. Este oficio fue detentado durante décadas por dos importantes familias moriscas bastetanas: los Muñoz Reduán (regidores de Baza) y los Enríquez Gilhaire.

Estos segmentos, privilegiados con oficios y mercedes (no olvidemos que tras negociar la capitulación que establecía el nuevo estatus de "cristianos nuevos" recibieron toda suerte de regalos, asignaciones anuales de la Corona, exenciones fiscales y otros honores) ${ }^{17}$, eran en su mayoría de nuevo cuño. Surgieron al calor del poder de la Monarquía ya que la mayoría de los nobles musulmanes emigraron al Norte de Africa y pronto comenzarían a distanciarse del conjunto de la comunidad. Con el establecimiento de la farda como un impuesto ordinario los moriscos acomodados de la tierra de Baza procuraron gestionar su no inclusión dentro de los padrones del impuesto, a imitación de los hidalgos cristianos. Con ello conseguían además de un substancial ahorro un incremento en algo tan importante en la sociedad castellana de la Edad Moderna como el honor. Existían varias formas de conseguir la exención de los servicios. Una de ellas consistía en demostrar que el interesado se había bautizado voluntariamente antes de la conversión general, con lo cual se le consideraba legalmente como "cristiano viejo". A partir de la segunda década del siglo, precisamente cuando se establece ya definitivamente el impuesto y se incrementan las medidas represoras contra la minoría, muchos moriscos bastetanos consiguieron de la Corona su reconocimien-

15. Galán Sánchez, A.: Los mudéjares del reino de Granada, Granada, 1991, pp. 139-140.

16. Sobre el particular cfr. VINCENT, B.: «Las rentas particulares del Reino de Granada en el siglo XVI: Fardas, Habices, Hagüela», Andalucía en la Edad Moderna: economía y sociedad, Granada, 1985, pp. 81-122 y CASTILLO FERNÁNDEZ, J.: «Administración y recaudación de los impuestos para la defensa del reino de Granada: la Farda de la Mar y el Servicio Ordinario (1501-1516)», Areas. Revista de Ciencias Sociales, 14, 1992, pp. 67-90.

17. LADERO QueSADA, M. A.: Granada después de la conquista: repobladores y mudéjares, Granada, 1988, apéndice documental $\mathbf{n}^{\circ} 151$. 
to legal como cristianos viejos ${ }^{18}$. No hace falta señalar que la mayoría de ellos no tenían nada que ver con el medio centenar de humildes conversos voluntarios de finales del siglo XV. La creencia ciega en este tipo de documentos, que habría que contrastar más detenidamente, ha confundido a muchos historiadores que no han tenido empacho en aceptar la versión interesada de estos moriscos "cristianos viejos". Sin embargo, no creemos que la Corona se dejase engañar sino que así premiaba y reforzaba a leales colaboradores entre las élites de la minoría, lo cual le permitía controlar mejor a la comunidad sometida.

Otra de las opciones era la de demostrar que se era noble de origen musulmán, lo que automáticamente si iba unido a buenos servicios a la Corona y a una posible sincera conversión equivalía al estatus de hidalgo.

Todas estas cualidades iban definiendo poco a poco a los moriscos ricos y poderosos del resto de su congéneres. Ya sólo faltaban algunos atributos externos que los diferenciaran definitivamente de la masa. Por ejemplo eludir legalmente toda una serie de prohibiciones impuestas a los neocristianos. Un rasgo distintivo de ser un morisco leal y prácticamente noble era el de poseer y portar armas, algo totalmente vedado y perseguido por la justicia ${ }^{19}$. Las solicitudes de licencias de armas por parte de notables moriscos, con o sin cargos institucionales, fueron muy frecuentes. A partir de 1560 se prohibió a los moriscos granadinos poseer esclavos negros, pues la Corona temía que los siervos se convirtieran al Islam al contacto con sus amos. A partir de entonces, uno de los empeños de todo poderoso morisco que se preciara se cifró en conseguir permiso para conservar sus esclavos de color ${ }^{20}$.

$\mathrm{Si}$ a todo ello le unimos otros signos y gestos externos como el de poseer caballo, vestir a la castellana, contar con casas y mobiliario de tipo cristiano y relacionarse con cristianos viejos tenemos encuadrado perfectamente el típico morisco medrador y colaboracionista. Todo ello sin olvidar el importantísimo aspecto de la religiosidad externa en la que se convirtieron en au-

18. En 1518 Pedro de Marquina Zalé, vecino de Baza, consiguió una licencia de exención de la farda por ser "christiano viejo" ya que se había bautizado en Antequera, a la edad de siete años, antes de la conversión general. La misma gracia disfrutaba Gonzalo de Baeza Antequerí, vecino de Zújar, desde el año 1519. Se habría convertido a la edad de doce años, varios antes del de 1500 . Ambos habían aceptado el bautismo contra la voluntad de sus padres, habían casado con cristianas viejas y habían servido militarmente a la Corona, el primero en Perpiñán y en la toma de Lanjarón y el segundo en Orán (Archivo de Protocolos de Granada, sección histórica, sala V, distrito de Baza (en adelante A.P.G.), n² 8, 1520, ff. 719 y 896 respectivamente).

19. LÓPEZ DE COCA CASTAÑER, J.E.: «Los moriscos malagueños, ¿una minoría armada?», Estudios sobre Málaga y el reino de Granada en el V centenario de la conquista, Málaga, 1989, pp. 329-350.

20. Núñez Muley cifraba, hacia 1566, en su conocido memorial que los moriscos que poseían negros eran tan sólo unos cien en todo el reino (FoulCHE-DELBOSC, R.: «Memoria de Francisco Núñez Muley", Revue Hispanique, 1899, p. 231). Sin duda un verdadero lujo y todo un símbolo de un determinado estatus social. 
ténticos campeones (memorias, capillas, mandas piadosas, procesiones, miembros de cofradías, comunión y confesión diaria...).

Esta aparente normalidad y pacífica coexistencia se veía amenazada por la obstinación de la Corona en hacer desaparacer las señas de identidad de los moriscos granadinos. No se trataba ya de una mera cuestión religiosa sino de los rasgos culturales que les eran propios como trató de demostrar en vano en su conocido memorial el venerable Fernando Núñez Muley. Las inapelables pragmáticas promulgadas por Felipe II llevaron a la rebelión desesperada de buena parte de los moriscos granadinos. Nuestra comarca, rodeada de importantes focos rebeldes (Cenete, Almanzora, Galera) aguantó durante todo el conflicto. Ninguno de los pueblos de su alfoz se rebeló de buena gana. Hubo un intento infructuoso de los moriscos del Almanzora por levantar Caniles $^{21}$. En septiembre de 1569 un escuadrón rebelde penetró en Cúllar llevándose consigo, y por la fuerza, al vecindario morisco del pueblo ${ }^{22}$.

¿Cuál fue la reacción de los moriscos bastetanos ante el conflicto? En principio la contraria de la que se esperaría por su origen étnico. Si bien es verdad que una minoría huyó a las sierras para unirse a los alzados, un importante contingente se unió a las tropas del marqués de los Vélez que penetraban desde el Reino de Murcia para aplacar la Alpujarra Oriental. En un reciente trabajo de Sánchez Ramos, realizado con memoriales de servicios custodiados en Simancas, se ha puesto de manifiesto la importante ayuda que muchos moriscos prestaron para destruir a sus correligionarios rebeldes. La mayoría de ellos procedía de zonas de población mixta, fundamentalmente de la ciudad de Baza y de su jurisdicción ${ }^{23}$. Esta era sin duda la prueba definitiva de lealtad. Pero no debemos creer que lo hacían desinteresadamente sólo por congraciarse con el poder castellano. Moriscos bastetanos participaron desde el comienzo del conflicto en golpes de mano y operaciones de rapiña contra los rebeldes como se comprueba en los protocolos notariales obteniendo todo tipo de bienes muebles: esclavos, ganado, ropas o joyas. Algunos de ellos también sufrieron la violencia y el pillaje de sus correligionarios sublevados.

A pesar de la fidelidad, pasiva o activa, demostrada durante el conflicto la mayoría de los moriscos de Baza y su tierra fueron expulsados a finales de

21. Foulchè-Delbosc, R.: «Documents relatis a la Guerre de Grenade», Revue Hispanique, 1914, p. 518.

22. A.G.S., Cámara de Castilla (en adelante C.C.), leg. 2152.

23. SÁNCHEZ RAMOS, V.: «Los moriscos que ganaron la guerra», Mélanges Louis Cardaillac, Centre d'Etudes et de Recherches Ottomanes, Morisques, de Documentation et d'Information, Túnez (en prensa). Hasta hace poco casi se desconocía esta participación activa de moriscos del lado castellano, lo que seguramente no entendían los defensores, antiguos y modernos, de la inasimilación y de la imposible convivencia. El único ejemplo conocido de morisco enrolado en las tropas cristianas, aunque por motivos de venganza, era el del famoso Tuzaní, inmortalizado por Pérez de Hita y Calderón de la Barca. 
1570, pasando sus bienes inmuebles a propiedad de la Corona. Las fincas de moriscos de la ciudad se arrendaron y/o vendieron entre los cristianos viejos del lugar, como hemos analizado recientemente en sendos trabajos ${ }^{24}$. Las de las villas de la jurisdicción se repartieron entre los repobladores llegados desde diversos puntos de la Península, fundamentalmente de Murcia, La Mancha y sur del Reino de Valencia.

A pesar de todo, muchos cristianos nuevos de nuestra comarca abrumaron con un rosario de reclamaciones y de memoriales de servicios al Tribunal de los Tres Jueces, un juzgado creado ex profeso por la Corona para dilucidar este y otro tipo de atropellos cometidos durante el conflicto y de devolver, en su caso, las propiedades confiscadas. Algunos neoconversos, casi cuatrocientos hacia 1578, consiguieron su objetivo: permanecer legalmente en su patria $^{25}$. Los menos, además, consiguieron tras años de litigio recuperar sus bienes. Hubo quien incluso aumentó su patrimonio a partir de las ventas de predios de sus antiguos correligionarios. A finales del siglo XVI en lugares como Caniles y Benamaurel no parecía extraño que varias haciendas de las repartidas a los colonos pertenecieran ya a familias moriscas.

Sin embargo, la amenaza de la expulsión continuaba. La famosa "resaca" de moriscos de 1584 llevó al exilio a más de medio centenar de moriscos bastetanos ${ }^{26}$. La definitiva expulsión de 1609-1614 también afectó a la zona. Precisamente en esos años aumenta el número de litigios de hidalguía por parte de familias de origen morisco que pretenden, y en algunos casos consiguen, probar su noble origen y de paso escapar al destierro ${ }^{27}$.

Para evitar esta inseguridad los diferentes linajes de conversos que permanecieron en nuestra comarca reforzaron la estrategia que mejores resultados les había dado tradicionalmente: sus servicios militares a la Corona. Así, algunos descendientes de los Alférez, alguaciles de Zújar, participaron en el socorro de Cádiz durante el saqueo inglés de $1596^{28}$. Esta fidelidad fue corroborada sucesivamente durante los periodos bélicos del reinado de Felipe IV, especialmente en las jornadas de Portugal y Cataluña, y durante la Guerra de Sucesión a comienzos del siglo XVIII; algo que no sería exclusivo de la comarca. Otros linajes de ascendencia morisca actuaron de forma similar, como

24. CAstillo FERnÁndez, J.: "Arrendamientos de bienes confiscados a moriscos en Baza y su Tierra (1571-1616)», Chronica Nova, 21, Granada, 1993-94, pp. 63-98 y «Las propiedades de sus vecinos...».

25. VINCENT, B.: «Los moriscos que permanecieron en el Reino de Granada después de la expulsión de 1570», Andalucía en la Edad Moderna: economía y sociedad, Granada, 1985, p. 270.

26. LAPEYre, H.: Geografia de la España morisca, Valencia, 1986, p. 156.

27. Cfr. el caso de varias familias moriscas de la comarca de Baza que lograron esquivar todas las expulsiones durante varios siglos. CAstıLlo FERNÁNDEZ, J.: «Hidalgos moriscos: ficción histórica y realidad social. El linaje de los Enriquez Meclín de la Tierra de Baza (siglos XVXVIII)», Mélanges Louis Cardaillac (en prensa).

28. Archivo Histórico Provincial de Avila, sección Ayuntamiento, leg. 71, expediente 14-7. 
los Bazán de Abla y Fiñana o los Aranda Sotomayor y los Figueroa de Granada capital ${ }^{29}$.

Pero faltaba algo más todavía que legitimara su ascendencia. Nada mejor que una falsificación documental que demostrara para siempre su limpieza de sangre, la nobleza de su origen, su ortodoxia católica y su fidelidad a la Monarquía. El paso del tiempo facilitó las cosas pues la memoria enflaquecía y daba paso a la reelaboración imaginaria de la historia del linaje, obteniendo así un curioso sincretismo entre ambas culturas; algo ya conocido en ámbitos como el religioso cuyo máximo exponente fue la falsificación de los Libros Plúmbeos del Sacromonte.

\section{UN EJEMPLO CONCRETO: LUIS ENRÍQUEZ XOAIDA}

El Protocolo o promptuario para el más fácil uso de el archivo de el Hospital de Santiago de esta ciudad de Baza, e individual noticia de sus posesiones según el estado que tienen en este año de 1774, custodiado en el Archivo Municipal de Baza, recoge entre las propiedades de esta institución la de un huerto conocido como de Luis Enríquez Joaida. La anotación que aparece en el libro afirma lo siguiente:

"El excelentísimo señor don Enrique Enríquez de Guzmán, fundador del Hospital del señor Santiago tubo por hijo bastardo a Luis Enríquez Joaida, el qual lo huvo en María la Zarca, que antes se llamaba Joaida de Alifaz, mora. Y habiéndolo reconocido por tal hijo bastardo le hizo un legado en el qual, entre otras posesiones, le donó un huerto con su casa principal en la calle del Chorrillo cuya casa está ya arruinada y su solar incorporado en el huerto (...). El qual huerto nunca ha salido de la familia de estos bastardos hasta aora que Pedro y Gregorio Enríquez, hermanos, sus últimos poseedores de mancomún lo vendieron al Hospital de señor Santiago en el precio de 2.499 reales...".

Efectivamente, el 23 de septiembre de 1778 los hermanos Enríquez enajenaron esta finca a favor de los frailes de San Jerónimo de Baza, administradores de la institución benéfica. En la escritura de compraventa se recogía igualmente la condición de esta familia como descendientes del noble cristiano y de la musulmana ${ }^{30}$. Llama la atención que a finales del siglo XVIII un linaje se jactara de su procedencia conversa y bastarda en medio de una sociedad rural aún bajo el influjo del espíritu contrarreformista y barroco.

Para comprender las causas últimas que produjeron esta supuesta genealogía debemos remontarnos varios siglos atrás. En primer lugar conviene

29. Ruz Márquez, J. L.: «Los Bazán de Abla y Fiñana, un linaje de conversos», Homenaje al padre Tapia, Almería, 1982, p. 410 y LERA GARCÍA, R. DE: «Criptomusulmanes ante la Inquisición granadina en el siglo XVIII», Hispania Sacra, 74, 1984, pp. 532 y 534.

30. A.P.G., $n^{\circ} 1180,1778-1780$, vol. I, f. 228. 
aclarar quién fue Enrique Enríquez de Guzmán. Este aristócrata castellano, fiel servidor regio, vivió a caballo entre los siglos XV y XVI. Del linaje de los Almirantes de Castilla y de los Condes de Alba de Liste, ocupó cargos de máxima confianza en la corte de los Reyes Católicos, siendo su mayordomo mayor además de comendador de la Orden de Santiago. Sus tareas institucionales no constituían el único vinculo con la Monarquía ya que era tío carnal de Fernando el Católico ${ }^{31}$. Participó activamente en las Guerras Civiles a la sucesión del trono castellano y en la Guerra de Granada, aparte de otras actividades diplomáticas. Tras la conquista de Baza fue designado Justicia Mayor y Gobernador de la ciudad cuyos destinos regiría su linaje durante varias centurias. Casado con la noble doña María de Luna, nieta del valido de Juan II de Castilla, tuvo cuatro hijas que enlazaron con lo mejor de la aristocracia peninsular (duque de Gandía, marqués de Priego, marqués de Denia...). Tras una larga vida dedicada al servicio real falleció en 1504.

Su influencia en la ciudad de Baza y sus alrededores, lugar donde asentó su casa, fue enorme. Controló mediante deudos y criados su concejo, obtuvo gran cantidad de propiedades en su repartimiento, además de obtener varios señoríos en su entorno y de adquirir mediante compras infinidad de tierras. Su ascendencia sobre la comunidad musulmana fue muy relevante y creemos que influyó decisivamente en las conversiones voluntarias de finales del siglo XV. La falta de un hijo varón impidió que esta familia llegara a ser una de las más relevantes de Castilla. Sus descendientes no pasaron de ser unos nobles de alcurnia en una pequeña ciudad de la periferia.

Por supuesto no está demostrado que tuviera un hijo con una musulmana conversa bastetana. En su testamento, otorgado poco antes de fallecer, no se recoge ningún tipo de legado a este supuesto bastardo ${ }^{32}$. De haber sido así este vástago habría nacido en un lapso que iría entre la conquista de Baza (1489) y el año de su muerte (1504). El hecho de que la hipotética madre, María la Zarca ("de ojos azules"), se hubiera convertido al cristianismo estrecharía aún más esta posible cronología. No existe ninguna prueba documental de la época que demuestre la existencia de esta mujer y su relación con el anciano don Enrique. El que estos bastardos tuvieran el apellido del noble tampoco prueba nada pues es bien sabido que en las conversiones masivas de comienzos del XVI la mayoría de los neófitos adquirieron los patronímicos de personajes de alcurnia ${ }^{33}$ y en la comarca de Baza los más importantes

31. Nacido del matrimonio de Juan II de Aragón y Juana Enríquez, hermana de don Enrique. De esta relación de parentesco procede el lema del escudo de los Enríquez: "Reyes de Nos e Nos non de Reyes".

32. Lo otorgó, junto a su esposa, en Medina del Campo el diez de abril de 1504. Un codicilo realizado seis días más tarde tampoco hace referencia alguna a este tema (Real Academia de la Historia, Colección Salazar y Castro, M-45, ff. 6-8).

33. LADERO QUESADA, M.A.: «Nóminas de conversos granadinos (1499-1500)», Los mudéjares de Castilla y otros estudios de Historia Medieval Andaluza, Granada, 1989, p. 143. 
eran los Enríquez. No es de extrañar, por tanto, que fuera el apellido más habitual entre los moriscos de la región. Entre los linajes más relevantes que lo adoptaron destacaban los Enríquez Meclín, alguaciles de Benamaurel, los Enríquez Gilhaire de Baza, repartidores de la farda y los Enríquez Abenzuleime, alguaciles de Caniles. El patronímico de su esposa, Luna, también se adoptó frecuentemente por los nuevamente convertidos.

A pesar de todas estas objeciones Luis Enríquez Xoaida existió efectivamente, aunque su nacimiento se produjo algunos años más tarde. No tenemos datos acerca de esta familia hasta mediados del siglo XVI, pues con anterioridad no parece que fueran especialmente relevantes en la vida bastetana ${ }^{34}$. Luis Enríquez Xoaida fue un rico mercader bastetano que debió nacer hacia la década de 1530 . Sus verdaderos padres fueron los moriscos Pedro Xoaida y María de Santolalla. En todos los documentos de la época aparece inequívocamente como morisco y pechero y no se hace referencia alguna a su supuesto parentesco con los señores del Estado de Baza. Esta invención, sin duda, se debió fraguar por sus descendientes entre los siglos XVII y XVIII cuando ya el linaje de los aristócratas se había extinguido.

Nuestro interés por este personaje no sólo deriva de su imaginario origen sino de su actitud personal. Como hemos señalado Xoaida era uno de los mercaderes más ricos de Baza. No en vano pagaba en los repartimientos de la farda la cuarta pecha más cuantiosa de todos los conversos bastetanos. Sus objetivos comerciales estaban muy diversificados: textiles, ganados, cereales... ${ }^{35}$; además de intervenir en la cobranza de impuestos reales y señoria$\operatorname{les}^{36}$. Sus propiedades rústicas eran, asimismo, muy cuantiosas destacando las tierras de regadío y los bienes urbanos (casas, solares, un horno), todos en torno al barrio de la Morería donde residía. Como el resto de labradores moriscos bastetanos también poseía algunos viñedos, tierras de secano y majadas para el ganado.

34. La primera referencia a un posible miembro de esta familia la encontramos a finales del siglo XV. Se trata del anciano musulmán Zahad Joaide que testificó a favor de don Enrique Enríquez en un pleito con el concejo de Baza por la titularidad del término de Campo Cámara (Archivo de la Real Chancillería de Granada, en adelante A.R.Ch.G., 402/3381/13).

35. En los protocolos de la época aparecen infinidad de cartas de venta al por menor otorgadas por Xoaida de telas (paños venticuatreños, jergas) y de ganado mular. Pero también realizaba grandes negocios. En 1562 convino con un transportista el traslado de 2.000 fanegas de trigo desde Baza, Zújar y Benamaurel hasta Murcia y Cartagena (A.P.G., n 128, 1562, f. 437).

36. En marzo de 1562, acompañado de otro morisco bastetano, se constituyó en fiador de las Tercias Reales de los pueblos de la jurisdicción bastetana, por valor de casi $400.000 \mathrm{mrs}$. Seis años más tarde era el cobrador de las minucias de la villa de Galera, señorío de los Enríquez, valoradas en más de 100.000 mrs (A.P.G., n 128, 1562, f. 192 v y n 114, 1568, f. 110). 
PATRIMONIO DE LUIS ENRÍQUEZ XOAIDA (1570) ${ }^{37}$

\begin{tabular}{|c|c|c|c|c|}
\hline Inmueble & Ubicación & Extensión & Linderos & Otros bienes \\
\hline casas principales & Barrio Chorrillo & & & \\
\hline corral cercado & Barrio Chorrillo & & casas de Xoaida & \\
\hline horno de bizcocho & Barrio Chorrillo & & huerta de Xoaida & \\
\hline 8 casas pequeñas & Barrio Chorrillo & & $\begin{array}{l}\text { unas con otras } \\
\text { y corral de Xoaida }\end{array}$ & \\
\hline huerta & $\begin{array}{l}\text { Acequia } \\
\text { B. Francés }\end{array}$ & $\begin{array}{l}8 \\
\operatorname{cs} 3 / 4\end{array}$ & & \\
\hline secano & $\begin{array}{l}\text { Acequia } \\
\text { B. Francés }\end{array}$ & $7 \mathrm{fs}$ & huerta anterior & \\
\hline huerta cercada & $\begin{array}{l}\text { Acequia } \\
\text { B. Francés } \\
\text { (brazal Santolalla) }\end{array}$ & 11 & 2 morales & \\
\hline 2 bancales & $\begin{array}{l}\text { Acequia } \\
\text { B. Francés } \\
\text { (brazal Santolalla) }\end{array}$ & $\begin{array}{l}8 \mathrm{cs} \\
1 / 4\end{array}$ & Xoaida & \\
\hline huerta cercada & $\begin{array}{l}\text { Acequia } \\
\text { B. Francés }\end{array}$ & $7 \mathrm{cs}$ & horno de Xoaida & 5 morales, 1 olivo \\
\hline 27 bancales & $\begin{array}{l}\text { Pago Almozala } \\
\text { (brazal de las } \\
\text { Monjas) }\end{array}$ & $10 \mathrm{fs} 4 \mathrm{cs}$ & unos con otros & árboles frutales \\
\hline $\begin{array}{l}3 \text { bancales } \\
\text { cercados }\end{array}$ & $\begin{array}{l}\text { Acequia Mayor } \\
\text { (brazal Puerta } \\
\text { de Caniles) }\end{array}$ & $4 \mathrm{fs}$ & & \\
\hline 2 bancales & Pago Fontezuelas & $2 \mathrm{fs} 5 \mathrm{cs}$ & & \\
\hline 2 bancales & Acequia Pliego & $2 \mathrm{fs}$ & & \\
\hline 17 bancales & Acequia Pliego & $13 \mathrm{fs} 7 \mathrm{cs}$ & & \\
\hline viña & Pago de Zalema & $21 / 4$ marjales & & \\
\hline haza de secano & $\begin{array}{l}\text { Cañada } \\
\text { de los Cerrillos }\end{array}$ & $7 \mathrm{fs}$ & & \\
\hline haza de secano & Cortijo Santacruz & $3 \mathrm{fs}$ & & \\
\hline cañada de secano & Rambla Honda & $10 \mathrm{fs}$ & & \\
\hline 2 hazas secano & $\begin{array}{l}\text { Rambla } \\
\text { de las Tejeras }\end{array}$ & $13 \mathrm{fs}$ & & \\
\hline corral de ganado & Campo de Zabroja & & & \\
\hline
\end{tabular}

37. Abreviaturas. Fs: fanegas, cs: celemines. La fanega de Baza, al igual que la cordobesa, tenía 12 celemines o 400 estadales. El estadal cordobés medía 9'1815 m2. El marjal era diferente al granadino pues tiene 133' 3 estadales en lugar de 100; es decir, 1 fanega = 3 marjales. 
También poseía a censo algunos de los bienes inmuebles pertenecientes a los propios del concejo ${ }^{38}$. Aunque no contaba con oficios públicos, honores ni exenciones fiscales no dejaba de ser uno de los más acomodados burgueses de la sociedad bastetana del seiscientos.

El joven y ambicioso Xoaida, al igual que otros ricos conversos, no quería que se le identificara con los desheredados moriscos de su entorno. Por ello trataba por todos los medios de diferenciarse, al menos exteriormente, del común de sus correligionarios. En una información solicitada por él mismo en 1562 cuatro cristianos viejos nada sospechosos de veleidades filomoriscas (dos escribanos, un notario de la iglesia y un regidor bastetanos) declararon que Luis Enríquez estaba totalmente integrado en la sociedad cristiana $^{39}$. Los rasgos que le definían eran los de buen cristiano que acudía frecuente y voluntariamente a misa, comulgando y confesando, que vestía y comía según los usos castellanos, poseía caballo y se servía de mozos cristianoviejos ${ }^{40}$. Entre sus amistades se contaba lo más granado de la sociedad bastetana, relacionándose habitualmente con ella. Incluso había solicitado al obispo de Guadix labrar una capilla privada en la parroquia de San Juan. Por ello también solicitó a la Corona la merced de poseer esclavos negros cuando esta posibilidad se prohibió a los descendientes de musulmanes a comienzos de la década de los sesenta ${ }^{41}$.

Sus vecinos, por tanto, no tenían por qué dudar de la sincera y deseada asimilación de este mercader morisco. Si les quedaba alguna sombra de sospecha ésta se disiparía al estallar la sublevación de los moriscos alpujarreños en la Navidad de 1568. Al igual que otros muchos acaudalados conversos de Baza y su alfoz, Luis Enríquez se alineó sin titubear al lado de la Corona y de sus vecinos cristianos. La situación de todos ellos, aunque opresiva, no les había empujado a una alocada rebelión en la que tenían mucho que perder. Nuestro personaje tampoco perdió el tiempo a la hora de demostrar su fidelidad. A los cuatro días del estallido de la sublevación, el 28 de diciembre, el

38. Concretamente cinco solares en el "Almocaber" o antiguo cementerio musulmán, extramuros de la ciudad, por los que abonaba anualmente $902 \mathrm{mrs}$. al mayordomo municipal (Archivo Municipal de Baza, en adelante A.M.B., Libro de Censos del Concejo). El hecho de que no tuviera reparos en poseer terrenos situados sobre las tumbas de sus antepasados quizás ilustre mejor que nada esta voluntad de asimilación.

39. A.P.G., $n^{\circ} 128,1562$, f. 475.

40. A este respecto llama la atención la siguiente afirmación de Nicolás Cabrillana: "a pesar de que ambos grupos sociales se necesitaban, sus relaciones laborales quedan reducidas al mínimo. Los cristianos viejos prefieren contratar cristianos viejos, y los moriscos prefieren a los de su raza. Sería interesante saber si un cristiano viejo se habría puesto al servicio de un morisco, en caso de ser contratado" (CABrillana CIEZAR, N.: Almería morisca, Granada, 1990, p. 136).

41. Parece ser que Xoaida obtuvo licencia para poseer este tipo de esclavos. Al menos sabemos que contaba con criados de esta raza, posiblemente de origen liberto. En plena guerra, noviembre de 1569 , Luis Enríquez cedió en venta a su criado de color, Cristóbal Bravo, dos censos de 86 ducados de principal (A.P.G., $n^{\circ} 225$, f. 766). 
concejo de Baza recibía a través de Xoaida una comunicación del licenciado Molina de Mosquera, alcalde del crimen de la Chancillería granadina acantonado en el castillo de la Calahorra, que conminaba a la defensa de la ciudad ante la posiblidad de la extensión del conflicto hacia el altiplano bastetano ${ }^{42}$.

Durante el cruel conflicto nuestro joven mercader no se limitó a realizar labores de avituallamiento a las tropas, de espionaje o de vigilancia de pueblos y escolta de convoyes. Con su caballo y armas, sin cobrar soldada alguna, se unió a las tropas del marqués de los Vélez y posteriormente a las de don Juan de Austria. Tuvo una muy destacada intervención en innumerables hechos de armas que se resumían, según una provisión real, de esta forma:

“Nos a servido en el rebelión y lebantamiento de los moriscos del dicho reyno con sus armas y cavallo a su costa, desde el prinçipio de él hasta que se allanó, hallándose sienpre en todas las ocasiones que se ofreçieron, espeçialmente en siete batallas y recuentros que hubo contra los dichos moriscos, que fueron la de Felid y la de Ohanez y en las dos de Verja y en la del barranco de Lucaynena y en el rompimiento del tirano don Hernando de Válor en el lugar de Válor y en el çerco y toma de Galera, alançenado y matando moros de poder, de los quales sacó y redimió çinco christianos que tenían cautivos" ${ }^{\prime 3}$.

Efectivamente, la documentación notarial demuestra que tanto él como su padre participaron activamente en acciones bélicas y de rapiña contra sus hermanos de raza ${ }^{44}$. En junio de 1569 Luis Enríquez liberó, a cambio de seis ducados, a dos esclavas moriscas "las quales ubo andando en el canpo y exército del muy eçelente señor marqués de los Vélez" ${ }^{\prime 4}$.

A pesar de sus destacados servicios, al finalizar la guerra sólo se le concedió como merced licencia para permanecer en el Reino de Granada. Sus cuantiosas propiedades fueron confiscadas por la Corona entre agosto de 1571 y marzo de 1572. Durante varios años fueron arrendadas a vecinos cristianoviejos aunque el propio Xoaida pudo disfrutar de alguna de ellas pagando un alquiler ${ }^{46}$. Paralelamente nuestro personaje realizó un amplio

42. A.M.B., Actas Capitulares, sesión 28-XII-1568. A pesar de todo un regidor, Francisco de Ahedo se mostraba reticente "porque el que truxo aviso del liçençiado Moxquera es christiano nuevo de los nuevamente convertido e no trahe carta firmada del dicho liçençiado Moxquera para que buelba la dicha gente ni çertificaçion de cosa alguna".

43. Real Provisión del Consejo de Hacienda y Población (Granada, 30-VIII-1576) (A.R.Ch.G., $202 / 5260 / 3)$.

44. En agosto de 1569 Pedro Enríquez Xoaida y otros dos moriscos vendieron a tres vecinos cristianos 511 cabras y ovejas "habidas de buena guerra" por algo más de 3.000 reales (A.P.G., $\mathrm{n}^{\mathrm{o}} 225, \mathrm{f} .425$ ).

45. María de Alcaraz, natural de Vícar, le había correspondido en el repartimiento hecho por el marqués en Félix y Mencía, natural de Beires, tras la batalla de Ohanes (A.P.G., n²25, f. 764).

46. Sus propiedades rentaron a la Hacienda Real durante el trienio 1571-1573 nada menos que 102.000 mrs. (A.R.Ch.G., 202/5260/3). 
despegue legal con objeto de recuperar sus propiedades y conseguir que sus padres permanecieran en $\mathrm{Baza}^{47}$. Multitud de memoriales con sus reclamaciones y sus servicios prestados se pueden rastrear en Simancas y en el Archivo de la Real Chancillería de Granada ${ }^{48}$. Por fin, en 1575 consiguió recuperar su propiedades y las cantidades que habían rentado durante su confiscación ${ }^{49}$. Tras contraer matrimonio, entre 1575 y 1582, con Isabel de Luna consiguió otra real provisión para que tanto su mujer como sus hijos heredaran sus posesiones una vez fallecido y pudieran quedar legalmente en el reino ${ }^{50}$.

La situación financiera de Xoaida debió de recuperarse a marchas forzadas puesto que accedió a una serie de bienes confiscados a otros moriscos, generalmente colindantes con propiedades suyas lo que le permitió redondear un importante patrimonio. Entre 1577 y 1579 dirigió sus inversiones a bienes rústicos: huertas, viñas y bancales de riego situados en los pagos tradicionales pertenecientes a moriscos, por un total de más de $241.000 \mathrm{mrs}$., si bien algunos de estos inmuebles fueron cedidos posteriormente a terceros. Entre 1583 y 1591 se dedicó a la adquisición de casas y solares en los barrios moriscos valorados en casi $20.000 \mathrm{mrs}^{51}$.

47. Siempre contó con el apoyo y certificaciones de importantes personajes como de don Juan de Austria, el marqués de los Vélez o don Pedro de Deza, presidente de la Chancillería granadina.

48. Memoriales y Reales Provisiones a favor de Xoaida se conservan en A.G.S., C.C., legs. 2176 y 2190 y Contadurías Generales, leg. 358 y en A.R.Ch.G., 202/5260/3. Entre los moriscos que cita Ana Herrera con licencia para permanecer en el reino aparece Luis Enríquez. Herrera Aguilar, A.S.: "La población morisca granadina a partir de 1570», Actas del I Congreso de Historia de Andalucía, Andalucía Moderna-II, Córdoba, 1978, p. 107.

49. En cualquier caso muchas de ellas estaban hipotecadas con censos. En la "relaçión de los moriscos que ay en el reino de Granada con horden de Su Magestad y por seises y regadores y conoçedores y otros ofiçios y del valor de sus bienes raizes que tienen", realizada en 1577, se afirmaba que "Luis Enríquez, posee sus bienes y según la averiguaçión que está hecha valen más los çensos que están sobre ellos que el valor dellos" (A.G.S., C.C., leg. 2181).

50. Real Cédula otorgada en Lisboa el 11 de junio de 1582 (A.R.Ch.G., 202/5260/3).

51. "Libro de remates de bienes de moriscos de Baza (1577-1590)" (A.R.Ch.G., 202/5260/3). Sobre el particular cfr. nuestro trabajo Las propiedades de sus vecinos... 


\section{BIENES DE MORISCOS ADQUIRIDOS POR LUIS ENRÍQUEZ XOAIDA (1577-1591)}

\begin{tabular}{|c|c|c|c|c|c|c|}
\hline Fecha & Tipo inmueble & Ubicación & Antiguo dueño & Extensión & Precio (mrs.) & Traspaso \\
\hline 14-III-1577 & huerto y casa & Acq. B. Francés & Hros. del Cenetí & & 854 & \\
\hline 14-III-1577 & huerto cercado & Acq. B. Francés & Luis el Haiti & 2 cs. 3 ests. & 7.897 & \\
\hline 10-XII-1579 & $\begin{array}{l}30 \text { pedazos } \\
\text { de viña }\end{array}$ & $\begin{array}{l}\text { Acq. B. Francés } \\
\text { (brazal Fco } \\
\text { López) }\end{array}$ & $\begin{array}{l}\text { Jerónimo } \\
\text { y Diego Jonud, } \\
\text { Lorenzo Xipi y } \\
\text { Gonzalo } \\
\text { Mofarrix }\end{array}$ & 9 mrjs. 2 ests. & 25.255 & Sí \\
\hline $10-X I I-1579$ & 5 bancales & $\begin{array}{l}\text { Acq. } \\
\text { Fontezuelas }\end{array}$ & $\begin{array}{l}\text { Hros. Diego } \\
\text { el Bainí }\end{array}$ & $5 \mathrm{fs} .3^{\prime} 5 \mathrm{cs}$ & 52.917 & Si \\
\hline 10-XII-1579 & $\begin{array}{l}3 \text { bancales } \\
\text { (y } 9 \text { morales) }\end{array}$ & $\begin{array}{l}\text { Acq. Mayor } \\
\text { (brazal Calle } \\
\text { Ancha) }\end{array}$ & $\begin{array}{l}\text { García Alhax y } \\
\text { Miguel Bayón }\end{array}$ & 1 fs. $6 \mathrm{cs}$. & 36.000 & Sí \\
\hline 10-XII-1579 & $\begin{array}{l}\text { huerta cercada } \\
\text { y casa }\end{array}$ & $\begin{array}{l}\text { Acq. B. Francés } \\
\text { (barzal } \\
\text { Santolalla) }\end{array}$ & $\begin{array}{l}\text { Hros. Juan } \\
\text { Abolahix }\end{array}$ & $3^{\prime} 5 \mathrm{cs}$. & 17.500 & \\
\hline 10 -XII-1579 & 8 bancales & Acq. Almozala & $\begin{array}{l}\text { Hros. Rafael } \\
\text { de Ermaz }\end{array}$ & $2 \mathrm{fs} .11 \mathrm{cs} .3 / 4$ & 100.897 & \\
\hline 23-IX-1583 & casa & Coll. San Juan & $\begin{array}{l}\text { Juan de Vélez, } \\
\text { negro }\end{array}$ & 48 varas $^{2}$ & 10.125 & \\
\hline $12-\mathrm{I}-1590$ & casa & Coll. San Juan & Diego Baquí & 26 varas $^{2}$ & 6.000 & \\
\hline 27-VII-1591 & solar & C/ Chorrillo & $\begin{array}{l}\text { viuda Cenetí, } \\
\text { Luis Herruz, } \\
\text { Luis Haitíy } \\
\text { Luis Aduzali }\end{array}$ & & 3.750 & \\
\hline
\end{tabular}

Sus continuas estancias en la Corte para hacer oír sus reclamaciones le convirtieron en apoderado de los más diversos negocios encargados por sus vecinos, como la compra de oficios públicos ${ }^{52}$. Mientras esto sucedía su mujer era la encargada de gestionar los negocios familiares que se resumían hacia 1585 en arrendamientos de bienes muebles e inmuebles (los adquiridos por aquellos años) y la compraventa de ganado, cereales y fibras textiles como lino y cáñamo ${ }^{53}$.

52. En 1585 recibió poder del receptor de Su Majestad en Baza para adquirit en la corte un oficio de procurador. Ese mismo año se obligó a cobrar una deuda al doctor Madera, médico de cámara del rey (A.P.G., $n^{\circ} 143,1585$, f. 65 y n ${ }^{\circ} 252$, f. 74).

53. A.P.G., $\mathrm{n}^{\circ} 252$, f. 74 . 
Del matrimonio entre Xoaida e Isabel de Luna nacieron al menos cuatro hijos: Luis, Juan, Diego y María, que siguieron disfrutando de los privilegios, morales y materiales, ganados por su padre, el verdadero precursor del linaje. Luis Enríquez Xoaida falleció a comienzos del siglo XVII ${ }^{54}$. La fama y la riqueza atesorada por este emprendedor comerciante debieron quedar en la memoria de sus descendientes que con el paso del tiempo lo convertirían, nada menos, que en primo hermano del Rey Católico.

\title{
APÉNDICE DOCUMENTAL
}

1562, octubre, 2. Baza.

Probanza de Luis Enríquez Xoaida para obtener licencia de posesión de esclavos negros. A.P.G., $\mathrm{n}^{\circ} 128,1562, \mathrm{ff} .475-476$.

\author{
El Rey.
}

Reverendo yn Christo, padre obispo de Guadix e vuestro provisor e vicario general e nuestro corregidor e juez de resydençia de la çiudad de Guadix e vuestro lugarteniente en la çiudad de Baça. Porque aviéndonos suplicado por parte de Luis Enríquez, vezino de Ia çiudad de Baça, deçendiente de christianos nuevamente conbertidos de moros de los moradores del nuestro reino de Granada que teniendo consyderaçión a que a bivido y bive como christiano viejo y concurren en su persona otras calidades para poder servirse de esclavos negros, fuésemos servido de dar liçençia para que sin enbargo de un capítulo de las Cortes que [ce-]lebramos en la çiudad de Toledo el año pasado de [mill] e quinientos y sesenta en que dispone que ningún n[-uevamente convertidos] de estos reinos puedan tener esclavos negros. Y de la provisión que en declaraçión dello después dimos, librado por los del nuestro consejo, pudiesen tener los dichos esclavos negros según e como los tienen e pueden tener los christianos viejos. Queremos saver qué persona e qué calidad, vida, costunbres y exerçiçio es el susodicho y si de darle liçençia para tener dichos esclavos negros seguirían algún ynconbeniente, ansy en lo que toca a la fee como otras consyderaçiones e por qué causa. Os encargamos e mandamos que ynformados particularmente de la verdad de lo susodicho y de lo demás que çerca dello os pareçiere devemos saver. Sobre lo qual os encargamos la conçiençia nos enbieis relaçión del dicho negoçio. La qual, juntamente con nuestro pareçer firmado de vuestros nonbres, cerrada y sellada enbiareis al Nuestro consejo de la Cámara syn entregarla a la parte para que la mandemos vere y prober sobre ello lo que más convenga. Fecha en Madrid a veinte y quatro de jullio de mill y quinientos y sesenta e dos años. Yo, el rey. Por mandado de Su Majestad, Francisco de Heraso.

\section{Testimonios:}

-Juan de Salazar, escribano, 36 años. Conoce a Xoaida desde hace 20 años, "en todo el qual dicho tienpo e visto a Luis Enríquez en ábito y estofa de honbre de bien buen [ch-

54. Su fallecimiento se produjo entre los años 1604 y 1617. 
ristiano], temeroso de Dios Nuestro Señor, haziendo obras de tal, oyendo [misa] e sermones". Ha oído decir a los beneficiados de su parroquia "que el susodicho confiesa e comulga y haze muchas limosnas a christianos viejos e nuevos. E el trato de su casa es al modo de christiano viejo, sirviéndose en mesa alta con manteles; y con cavallo. $Y$ se sirve de moços christianos viejos (...) Y por esto crehe e tienen por çierto este testigo que de dar liçençia para poder tenere serviçio de esclavos negros...".

-Jerónimo de Aguilar, notario de la Iglesia Episcopal de Baza, 40 años. Conoce a Luis Enríquez desde que nació. Es hombre honrado y lo tiene por muy buen christiano "porque lo vehe en misa muchas vezes". Ha oído decir a los beneficiados de San Juan "que confiesa e comulga e haze limosnas como buen christiano y su trato es como tal en su casa. Se sirve como christiano viejo". Se sirve en mesa alta, tiene mozos cristianos viejos, caballos y se tratase como tal cristiano viejo "saliendo en regoçijo con los prinçipales de la çiudad". Podrá tener negros porque cree "que en su poder serán bien dotrinados en lo que conviene a ser buenos christianos".

-Francisco de las Casas, escribano público, 30 años. Conoce a Luis Enríquez de diez años acá. Lo ha tratado desde hace cinco años "y a entrado y salido en su casa muchas vezes". Lo ha visto andar en hábito de cristiano viejo y tratar y comunicar con ellos "y lo ha visto oyr misa muchos días syn llamallo en los padrones. $E$ munchas vezes que este testigo a visto salir el santísimo sacramento le a visto yr como christiano, y por tal lo tiene este testigo y lo tienen en esta çibdad (..) Y en su casa le a visto tener, este testigo, a la cabeçera de su cama cruzifijo y ymájenes de Nuestra Señora e otros santos e preçiarse de tenellas".

-Juan de Ahedo, regidor, 55 años. Lo conoce toda su vida y lo ha tratado y comunicado desde que el susodicho era muchacho. Trata con personas ilustres "oyendo misa en los días e fiestas, domingos y muchas vezes entre semana, reçando las oraçiones como christiano viejo, hincado de rodillas. $Y$ junto a este testigo se lo a visto rezar e las sabe". Su trato es con cristianos viejos, vistiéndose con ropas castellanas, siempre anda a caballo y tiene mozos cristianos viejos. "Quando come y çena en mesa e con manteles y con servilletas, beviendo vino e comiendo toçino (...) E no en nada a la morisca. E sabe porque el susodicho puso a este testigo para que tratase con el señor obispo y con el liçençiado Navero, su provisor, que le dexasen labrar una capilla en la yglesia de señor san Juan para su enterramiento que saliese a la calle, adonde está el Sacramento", a su costa y daría de limosna para la fábrica de la iglesia un censo de 30 y tantos ducados. "Y esto... trató e no se la dieron porque la querían para un clérigo... tiene tratado con este testigo de hazer un hospital y tiene ya so[lar] para ello y trahe los materiales para lo hazer... [Y es muy] limosnero que da munchas limosnas a christianos viejos y a christianos nuevos. E que es rico e tiene labor e ganado e tienda de mercader. $Y$ todos los criados que trae en el ganado y en la labor son christianos viejos. E convienen para el serviçio de su casas e lavor tener esclavos negros". 